\title{
Correction to: Oral Microbial Species and Virulence Factors Associated with Oral Squamous Cell Carcinoma
}

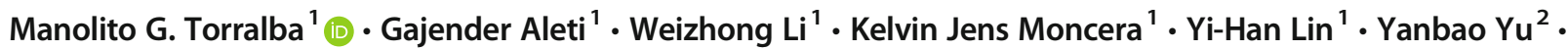 \\ Michal M. Masternak ${ }^{3}$. Wojciech Golusinski ${ }^{4}$. Pawel Golusinski ${ }^{4,5} \cdot$ Katarzyna Lamperska $^{6}$. Anna Edlund ${ }^{1}$. \\ Marcelo Freire ${ }^{1} \cdot$ Karen E. Nelson ${ }^{1}$
}

Published online: 20 November 2020

(C) Springer Science+Business Media, LLC, part of Springer Nature 2020

\section{Correction to: Microb Ecol} https://doi.org/10.1007/s00248-020-01596-5
The original article contained mistakes in the authors' affiliations. The original version has been corrected.

The online version of the original article can be found at https://doi.org/ 10.1007/s00248-020-01596-5

Manolito G. Torralba

mtorralb@jcvi.org

1 Department of Genomic Medicine, J. Craig Venter Institute, 4120 Capricorn Lane, La Jolla, CA 92037, USA

2 Department of Genomic Medicine, J. Craig Venter Institute, 9605 Medical Center Drive Suite 150, Rockville, MD 20850, USA

3 Burnett School of Biomedical Sciences, College of Medicine, University of Central Florida, 6900 Lake Nona Blvd, Central Florida Blvd, Orlando, FL 32827, USA

4 Department of Head and Neck Surgery, The Greater Poland Cancer Centre, Poznan University of Medical Sciences, Garbary 15, 61-866 Poznań, Poland

5 Department of Otolaryngology and Maxillofacial Surgery, University of Zielona Gora, Podgórna 50, 65-246 Zielona Góra, Poland

6 Laboratory of Cancer Genetics, Greater Poland Cancer Centre, 15th Garbary Street, Room 5025, 61-866 Poznan, Poland 